\title{
A falta de participação como fator limitante ao desenvolvimento das organizações cooperativas
}

\author{
Participation as lack of limiting factor for the development of cooperative organizations
}

\begin{abstract}
Resumo
O cooperativismo é tido como um dos principais instrumentos para a promoção do desenvolvimento econômico e social, mas para que as cooperativas atinjam esse estágio é necessária à participação dos cooperados, principalmente nas assembleias, sendo esse o órgão de maior representatividade da organização. Dessa forma o presente trabalho levantou a hipótese de que a não participação em assembleias se deve ao desinteresse e a falta de tempo dos médicos cooperados de uma cooperativa do ramo saúde. Para verificação dessa hipótese, foram utilizadas metodologias como a análise documental, revisão bibliográfica e pesquisa de campo, por meio de entrevistas semiestruturadas, o que levou a resultados como uma participação muito baixa nas assembleias dos últimos seis anos. Podemos concluir então, que essa cooperativa deve dispor de mecanismos internos de participação, confiança mútua e voluntarismo nas ações, além da adoção de um modelo adequado de participação, de baixo custo e alta representatividade.
\end{abstract}

Palavras chave: Cooperativismo, participação, assembleias.

\begin{abstract}
The cooperative is seen as a major instrument for promoting economic and social development. For the cooperative to reach this stage, participation of the members is needed, mainly in the assemblies, which are the most representative organ of the organization. Thereby, this study hypothesized that the non-participation in meetings is due to lack of interest and lack of time from the cooperative medical branch. The methodologies used to verify this hypothesis were: document analysis, literature review and field research, by semi-structured interviews, which demonstrated a very low participation in the meetings of the last six years. We could conclude that the cooperative must have internal mechanisms of participation, mutual trust and voluntarism in actions, besides the adoption of an appropriate model of participation, low cost and highly representative.
\end{abstract}

Keywords: Cooperative, participation, meetings.

Recebido: 28/11/2014 Aceito: 16/06/2015

Pablo Murta Baião Albino ${ }^{1}$ e Hugo Francisco Almeida ${ }^{2}$

${ }^{1}$ Universidade Federal de Viçosa, Doutor em Ciências Sociais Aplicadas - aplconsultores@yahoo.com.br

2 Universidade Federal de Viçosa, Bacharel em Cooperativismo - hugo.almeida@ufv.br 


\section{Introdução}

$\mathrm{O}$ cooperativismo e sua doutrina podem ser considerados um paralelo ao capitalismo e à lógica de exploração, pois esta forma de organização social adota princípios democráticos que incentivam a participação dos indivíduos além de distribuir os resultados do trabalho dos envolvidos. A forma societária que viabiliza o cooperativismo é a organização cooperativa, empreendimento definido pela Lei 5.764/71 no seu capítulo II artigo $4^{\circ}$ sendo uma sociedade de pessoas, com forma e natureza jurídica próprias, de natureza civil, não sujeita a falência, constituídas para prestar serviços aos associados, distinguindo-se das demais sociedades.

Um tema importante nas organizações cooperativas de acordo com Silva (1994) é a cooperação. Quando se discute esta questão podem ser feitas diferentes análises, principalmente no que tange a participação dos associados nas estruturas de gestão e governança.

Neste sentido, pode-se discutir a participação dos associados desde a fase em que as cooperativas se formam até aquela em que a participação econômica é necessária para o crescimento da organização, seja ele, impulsionado pelo mercado ou pela necessidade de geração de riquezas, internalizando a lógica econômica de maximização de resultados (BIALOSKORSKI NETO, 2004).

Diante da importância da participação na gestão e sobrevivência das organizações cooperativas, surge a dúvida: o que pode levar os cooperados a se associarem e não frequentarem as assembleias? Ao mesmo tempo, por que os sócios, em sua maioria, não se interessam pelas questões burocráticas da cooperativa? Estes comportamentos indicam um desvio da lógica cooperativista e, portanto, são passiveis de serem investigados para que se possam conhecer os motivos que levam uma pessoa a se tornar cooperado, parte de uma organização cooperativa e não participar das decisões inerentes à gestão do empreendimento, mesmo que os resultados gerados no negócio sejam diretamente revertidos ao próprio cooperado.

A cooperativa, que é objeto de pesquisa neste trabalho, é do ramo de saúde e vêm enfrentando um baixo nível de participação em suas assem- bleias gerais, o que vem dificultando suas ações e elevando o índice de insatisfação dos cooperados. Diante dos fatos, o objetivo deste trabalho é investigar o que leva os cooperados a se associarem a uma organização cooperativa uma vez que não participam de suas atividades.

Para tentar responder a estas perguntas e lançar luz sobre o problema da participação nas organizações cooperativas, o presente trabalho foi organizado em cinco partes, sendo a presente introdução, a revisão de literatura na qual são abordados trabalhos que discutem a importância da participação, suas causas e consequências. $\mathrm{Na}$ terceira parte do trabalho é apresentada a metodologia adotada para o desenvolvimento do mesmo. Na quarta parte são apresentados os resultados e a discussão e por último são apresentadas as considerações finais.

\section{Revisão de literatura}

\subsection{O movimento cooperativista e a valoração do homem}

O cooperativismo coloca o homem na posição de controlador da sua própria economia, onde o trabalho é valorizado e a produção é devolvida para que ele possa consumi-la ou determinar seu destino (CARNEIRO, 1981).

Segundo Pinho (2000), todo cooperado, independente de seu poder econômico e/ou político, tem direito a apenas um voto nas assembleias e as sobras, ao final de cada exercício social, são distribuídas na proporção de sua movimentação na cooperativa. Dessa forma, o cooperativismo pode ser entendido como um sistema econômicosocial que procura o interesse coletivo da produção e distribuição dos resultados.

Ao mesmo tempo, o cooperativismo é tido como um dos principais instrumentos para a promoção de desenvolvimento econômico e social ao gerar e distribuir renda, além de promover o capital social nas comunidades que o praticam (BIALOSKORSKI NETO, 2002). Por sua vez, o objetivo principal das cooperativas é proporcionar, aos seus cooperados, o bem-estar, ou seja, a função da cooperativa depende dos objetivos individuais de cada sócio (COOK, 1994). Alguns autores divergem com relação ao surgimento do cooperativismo. Para Noronha (2004), 
a história do cooperativismo apresenta uma relação direta com a história das organizações humanas em busca da autonomia social, sendo entendida como o processo no qual convivem, simultaneamente, âmbitos econômico, social e cultural. Culti (2006) reforça esta ideia argumentando que o surgimento do cooperativismo remete às origens do capitalismo, emergindo paralelamente, como um sistema participativo, democrático e mais justo para atender às necessidades e os interesses específicos dos trabalhadores, além de, propiciar o desenvolvimento integral do indivíduo por meio do coletivo. Desta forma, o cooperativismo pode ser admitido como um sistema e as cooperativas como unidades econômicas e espaços de convívio e transformações.

O cooperativismo, segundo a OCB (2004), pode ser entendido como movimento em função do qual crescem, mobilizam-se e consolidam as cooperativas e que tem a finalidade de difundir os ideais em que se baseiam para que haja desenvolvimento econômico e social em todas as sociedades. Este movimento é apresentado como a terceira via para o desenvolvimento, entre os modelos sinalizados pelo capitalismo e pelo socialismo.

Desse modo, Santos (2005) afirma que as cooperativas objetivando superar o modelo capitalista hegemônico, o qual é visto como determinante de regras concorrenciais e exploratórias de produção, ainda, se consolida como alternativa social de produção, não remetendo somente a uma remuneração igualitária a seus associados (donos), mas também a novas formas de sociabilidade solidária, baseadas no trabalho colaborativo e na participação democrática na tomada de decisões.

Portanto, uma cooperativa busca constantemente o crescimento e a conquista de espaço na economia e partindo dessa busca, objetiva atingir o social através da autonomia econômica e financeira dos próprios cooperados. De acordo com Pinho (1982), as cooperativas surgiram no Brasil no fim do século XIX (1891), vinculadas ao segmento consumo, recebendo sua primeira regulamentação legal por meio do Decreto n. ${ }^{\circ}$ $1637 / 1907$. A maior prova disso é que no período anterior a 1888 não havia condições para implantação do sistema cooperativista no Brasil, o que se justifica principalmente pela maior parte da mão de obra da época ser de escravos.

Neste sentido, Lima (1988) afirma que somente após a constituição republicana de 1891 , criou-se um ambiente favorável para o surgimento do cooperativismo no Brasil, viabilizado com o fim da escravidão e a intensificação da imigração europeia. Dessa forma, o cooperativismo brasileiro tem orientação voltada ao seu quadro social, buscando prioritariamente atender aos interesses dos cooperados, por outro lado, a cooperativa está inserida em um ambiente econômico, com capacidade de investir em estratégias comerciais para serem competitivas (BIALOSKORSKI NETO, 2002).

\subsection{A sociedade cooperativa e a importância da participação}

Diferentemente das sociedades de capital, as cooperativas são organizações que têm seu desenho empresarial baseado em uma fundamentação ideológica e doutrinária e são regidas por uma legislação específica. Ao contrário das sociedades de capital, em que o voto é proporcional ao capital de cada investidor, na cooperativa cada cooperado tem direito a um único voto nas decisões. Além disso, a repartição dos resultados considerados como sobras - ocorre proporcionalmente à dimensão da atividade de cada cooperado e não ao seu capital, como nas sociedades de capital. Geralmente, a forma particular de organização da empresa cooperativa faz com que ela busque maximizar os serviços aos seus associados e não os resultados das operações, o que pode afastá-la da maximização de resultados e do ótimo econômico (BIALOSKORSKI NETO, 1998).

Para Andrade (2009), as cooperativas podem ser compreendidas como sociedades autônomas, de ajuda mútua e controladas democraticamente pelos seus cooperados, que cumprem o dever de promover a educação e a formação de seus membros, representantes e funcionários. Estas organizações caracterizam-se por serem sociedades de pessoas democraticamente geridas, centradas nas necessidades do grupo, que unem esforços em torno de objetivos comuns, sendo mais importante a pessoa e não o capital. Além de apresentar aspectos simultâneos de associação e 
de empresa, norteada por princípios, valores e filosofia de natureza própria, o que a qualifica e a diferencia das demais organizações. Outra característica marcante é que os representantes eleitos pelos associados dirigem a organização e devem prestar contas à assembleia, na qual cada associado tem direito a um voto, conforme descrito no artigo 21 da Lei 5.764/71. Assim, a participação qualificada dos associados torna-se crucial para o desenvolvimento das cooperativas.

Schulze (1987) afirma que, nesse tipo de organização o associado como dono do empreendimento deve harmonizar sua participação quanto aos aspectos: político, econômico e gerencial. Dessa forma, pode definir seus objetivos e metas, seu capital e suas operações, bem como efetivar suas relações com o mercado. Sendo assim, as cooperativas, pode-se dizer, são o único setor da economia cuja doutrina tem sua ênfase no equilíbrio entre o econômico e o social, além dos desafios que muitas vezes são impostos pelos mercados, ainda têm que preservar suas relações com os cooperados, que são, ao mesmo tempo, donos, clientes e fornecedores. Assim, poderão cumprir com o seu papel principal de atender os anseios coletivos em detrimento dos anseios individuais.

Dessa forma, o comportamento organizacional dentro das cooperativas vem acompanhado de um dos princípios do cooperativismo que segundo Domingues (2002), é a educação, formação e informação, principalmente para estímulo e conscientização do papel do cooperado quanto à participação.

Ao mesmo tempo, Nascimento (2000), reforça a importância da participação apontando que a maioria dos problemas enfrentados pelas cooperativas, inclusive financeiros e gerenciais, podem ser resolvidos com a maior participação de todos os associados e isto passa pela educação, onde essa "ferramenta" é tida pelo autor como um meio para estimular a participação para resolução desses problemas.

Ainda, Ferreira e Presno (2008) comentam que, além da gestão empresarial, as cooperativas devem lançar mão da gestão social, ou seja, aquela que tem como objetivo consolidar o sentimento de pertencimento, de identidade dos associados com a cooperativa da qual fazem parte, para desta forma, alcançar a fidelidade e confi- ança do cooperado. A gestão social passa necessariamente pela educação e pela participação dos associados e de acordo com os autores, traduz-se em uma ferramenta imprescindível para permitir uma gestão cooperativa efetiva e eficiente, garantindo o desenvolvimento e a competitividade da cooperativa. A importância da educação no processo de fidelização, reciprocidade e participação dos cooperados nas atividades da cooperativa também é apresentada por Móglia et al (2004).

\subsection{Obstaculos à participação e suas conse- quencias}

Em síntese, pode dizer que a educação e a capacitação são os melhores respaldos para a administração de uma organização cooperativa, pois somente com a participação consciente e responsável do quadro social este empreendimento pode adquirir estabilidade e lograr um processo autogestionário.

Neste sentido, Lago (2008) afirma que a falta de educação cooperativista é a principal origem dos problemas de infidelidade e oportunismo do cooperativismo. Fato este que ocorre com frequência nas organizações cooperativas, onde a falta de participação propicia espaços para pessoas mal intencionadas a aproveitarem essa fragilidade para lesar a organização, desestimulando o cooperado que acaba infiel à cooperativa. Por tal motivo, a educação constitui um direito imprescindível ao quadro social e não um assunto a ser analisado quanto à sua conveniência ou não.

Nas organizações cooperativas também existe o problema do carona ou oportunismo que emerge quando os direitos de propriedade são não negociáveis, inseguros ou não atribuídos (COOK, 1995). Quando esse problema está presente na cooperativa, os cooperados preferem não investir ou participar, mas continuam na organização para aproveitar alguma situação favorável economicamente. A cooperativa acaba por beneficiar membros que agem de forma oportunista, obtendo somente vantagens com a organização cooperativa sem se relacionar de maneira direta com o empreendimento.

Adicionalmente, Cook (1995) apresenta um tipo mais complexo de oportunista em cooperati- 
vas, denominado insider free rider. A sua presença se configura à medida que novos cooperados entram na cooperativa e adquirem os mesmos direitos de propriedade que os antigos membros, que já pagaram pelos custos de geração das estruturas existentes. Essa possibilidade faz com que haja desincentivo ao investimento, por parte dos cooperados mais antigos. O problema do carona também é tratado por Fronzaglia (2005), segundo ele o associado que entra na cooperativa recebe o direito de transacionar, porém se ele participa ou não, é outro aspecto da transação.

\subsection{Estratégias para a falta de participação}

Olson (2007) ainda discute duas estratégias gerais para mitigar esse tipo de problema. A primeira é alterar o ambiente circundante à atividade coletiva, com o objetivo de construir mecanismos de exclusão física ou institucional para restringir o acesso aos benefícios coletivos. A segunda é criar incentivos alternativos, que recompensem a colaboração ou penalizem a não colaboração, ou a combinação de ambas - as recompensas e as punições. Algumas das estratégias incluem incentivos sociais e de ordem financeira, coerção e expulsão do grupo.

$\mathrm{Na}$ verdade, os princípios cooperativistas e a estrutura de uma organização cooperativa devem incentivar a participação e não penalizar a falta dela. Neste sentido, Schneider (1991) enfatiza que os associados devem ser estimulados permanentemente através da educação, comunicação e oportunidades em participar.

Ao mesmo tempo, Valadares (1995) argumenta que a participação dos membros regula as relações internas ou a divisão do poder de decisão e o controle entre os membros de uma cooperativa. $\mathrm{O}$ autor defende que a participação assegura a orientação das atividades de uma organização em benefício da maioria dos seus membros, ou pelo contrário, previne que a organização seja dominada por uma minoria de associados ou pelo seu corpo administrativo.

Bordenave (1983) comenta ainda que os processos participativos são entendidos como uma necessidade humana definida pelas circunstâncias sociais de um dado contexto histórico para a construção de espaços democráticos, fazendo referência à participação em seu sentido mais amplo de maneira completa, pois o cidadão que participa deve tomar parte, interferindo nas decisões de forma crítica e consciente com efetiva responsabilidade nos produtos resultantes do próprio processo de participação. Contraditoriamente, quando um ator social faz parte sem tomar parte não ocorre, por excelência, a concretude da participação em seu significado pleno.

Cabe ressaltar que essas considerações são premissas à condição da participação por meio do diálogo, potencializando assim a capacidade criativa do empreendimento, possibilitando à identificação de soluções de problemas que venham a promover a participação efetiva. Se em empresas a participação nas decisões e nos resultados é mais ou menos permitida, conforme a conveniência da própria empresa, na cooperativa a participação é exigida pelo próprio modelo, pois nela os cooperados são os donos, proprietários, usuários e fornecedores. Sem essa participação efetiva dos cooperados, não existe cooperativa legítima.

Além disso, a cooperativa também resgata a cidadania por meio da participação, do exercício da democracia, da liberdade e autonomia, podendo ser considerada uma das formas mais avançadas de organização da sociedade civil (MORATO e COSTA, 2001). A participação é o objetivo e o meio para se criar e manter uma cooperativa. Desta forma, a fim de participar da riqueza e benefícios gerados pelo seu trabalho é que as pessoas se unem nessa forma de sociedade. Ao mesmo tempo, a participação é o meio através do qual todos os sócios obtém o sucesso das metas socioeconômicas do empreendimento (LimbergER, 1996).

Segundo Abrantes (2004), para que haja participação, a gestão deve ser a mais democrática possível, devendo haver um sistema de decisões que propicie a participação de todos os associados. Para isso, é fundamental que haja uma estrutura perfeita e constante de comunicação e espaços que influenciem a participação de todos os sócios em todas as esferas de tomadas de decisão.

BIALOSKORSKI NETO (2007) discorre ainda sobre algumas características econômicas importantes no processo de participação como os custos de participação e cooperação para cada 
membro associado. Inicialmente há um custo da perda de parte de sua determinação econômica individual em favor do grupo de interesse da cooperativa, isto se expressa desde a necessidade de comercialização com regras comuns até o respeito às decisões majoritárias e igualitárias nas estruturas de governança e decisão, que muitas vezes podem ser contrárias aos interesses particulares de determinado associado. Também há o custo de participação que o regime de cooperação induz para o agente econômico sob o ponto de vista individual, ou seja, há um custo de oportunidade do tempo no processo de participação.

Ainda de acordo com o autor, a intensidade da participação pode ocorrer em proporção inversa aos custos de oportunidade do trabalho e aos custos de oportunidade do tempo de cada membro associado. Quanto maior estes custos, menor será a participação, isto é, toda vez em que há um custo de oportunidade significativo do fator de produção trabalho, esse não estimulará a participação nas estruturas de governança. Por outro lado, a participação poderá ocorrer se a importância econômica da decisão a ser tomada em assembleia for maior para o associado que a perda prevista pela ausência em seu trabalho diário. Esses custos ocorrem provavelmente, entre outros fatores, devido à relação entre o número de associados e a área geográfica de atuação da cooperativa. Uma área geográfica maior seguida de um quadro social maior pode dificultar tanto a participação do associado quanto o incentivo desta participação, por parte da cooperativa, em função do aumento dos custos de oportunidade.

De acordo com (FAMA, 1988 apud MENDES, 2001 ), esses aspectos derivam da Teoria da Agência, a qual analisa os conflitos e custos resultantes da separação entre propriedade e controle de capital. Essa possibilidade de não participação do cooperado nas decisões da organização, são nítidas nas sociedades por ações, que limita a responsabilidade do acionista para com a organização à parcela de capital que ele investiu. Este comportamento deveria ser distinto nas organizações cooperativas, uma vez que cada cooperado corresponde a um voto e o retorno das sobras é calculado mediante a participação do cooperado, características que deveriam incentivar a participação nestas organizações.
Para Hendriksen e Breda (1999), a Teoria da Agência é um modelo de tomada de decisão para mais de um indivíduo, que tem um enfoque prescritivo, embasado num modelo normativo, que envolve a teoria da utilidade. Neste modelo, onde um dos indivíduos é o agente e o outro é o principal, o primeiro cumpre certas tarefas para o segundo, o qual se compromete a remunerá-lo. O principal é o avaliador das informações e o responsável pela escolha do sistema de informação e o agente assume o papel de tomador de decisão, optando pelas melhores alternativas de decisão do ponto de vista do proprietário e das informações que a eles estarão disponíveis.

BIALOSKORSKI NETO (2007) também reafirma que a participação em empreendimentos coletivos, como as cooperativas, é de fundamental importância para gerar transparência de governança corporativa e assim minimizar os problemas de agência. $\mathrm{O}$ autor conclui que a maior participação dos associados é condição para o melhor desempenho da cooperativa. Entretanto, o próprio bom desempenho pode desestimular a participação, pois está inversamente relacionada com o aumento dos custos de oportunidade e do maior número de cooperados que advém normalmente com o bom desempenho. Isso gera um ciclo inverso na medida em que a menor participação exige custos adicionais de comunicação para suplantar a deficiência de transparência, o que prejudica o desempenho.

Dessa maneira, o associado, para participar mais, deverá perceber e obter maiores incentivos e benefícios compensatórios, em função dos custos e benefícios da sua participação. Esses benefícios devem compensar a maior divisão e a consequente diminuição de direitos à decisão e poder de voto nas cooperativas com um número muito alto de associados.

Porém, ainda podem existir problemas de participação devido ao fato de que as cooperativas apresentam uma estrutura de direitos de propriedade vagamente definidos e poucos incentivos contratuais para a participação (Bialoskorski Neto, 2004). Deste modo, tanto a cultura organizacional como o ambiente institucional podem ter influência na participação dos associados, uma vez que as cooperativas apresentam, em sua maioria, uma função objetivo de distribuição de resultados por meio da relação direta com o coo- 
perado e melhores preços imediatos e, assim, incentivam uma situação de direitos de propriedade vagamente definidos.

Para BIALOSKORSKI NETO (2004), as proposições de que a maior participação dos associados em cooperativas é condição para o melhor desempenho da organização são verdadeiras, contudo podem não ocorrer em realidade, o que é problemático, visto que a participação nas Assembleias Gerais Ordinárias (AGOs) pode estar negativamente correlacionada com o desempenho econômico, e a participação em comitês educativos também pode seguir este mesmo modelo.

A partir da revisão de literatura apresentada, o presente trabalho propõem lançar luz à seguinte questão: Porquê ser associado a uma cooperativa do ramo saúde, uma vez que não tem interesse em participar do seu principal instrumento de poder e de maior relevância que são as assembleias.

\section{Metodologia}

De acordo com GIL (1987), a metodologia tem como principal finalidade desenvolver, esclarecer e modificar conceitos e ideias com vistas na formulação de problemas mais precisos ou hipóteses pesquisadas para estudos posteriores.

O presente trabalho está baseado na revisão de literatura a respeito da participação dos cooperados nas organizações cooperativas. Também foram utilizadas as observações do pesquisador a respeito da participação nas assembleias de uma cooperativa do ramo de saúde localizada no leste do estado de Minas Gerais.

A coleta de dados primários é derivada do Programa de Organização do Quadro Social (OQS) promovido pelo Sindicato e Organização das Cooperativas do Estado de Minas Gerais (OCEMG). Este programa proporcionou a estada do pesquisador no período de setembro a dezembro de 2014 na cooperativa estudada.

Durante este período, a fim de melhor conhecer a organização foi feita análise nos documentos da cooperativa, como fichas de matrícula, estatuto social, regimento interno, atas das assembleias, lista de presença em assembleias, entre outros, chamando a atenção para o número de presença nas assembleias nos últimos seis anos
(2009 a 2014), onde todas ocorreram com a presença do quorum mínimo de associados. Também através desses documentos constatou-se o número de cooperados ativos e inativos presentes no quadro social da cooperativa.

Com o objetivo de comprovar as hipóteses levantadas no trabalho, foram realizadas pesquisas de campo na qual foram realizadas entrevistas semiestruturadas com os sócios da cooperativa. Esta técnica permitiu identificar alguns dos fatores que levam os cooperados a participarem ou não da sua organização cooperativa. Neste sentido, o método aqui utilizado permite o entendimento da realidade social e propicia uma percepção mais clara do que aquela codificada na linguagem dos dados (MINAYO, 1994).

Uma das vantagens de se utilizar essa técnica é a possibilidade do contato direto e pessoal do pesquisador com o objeto da investigação, permitindo acompanhar as experiências diárias dos sujeitos e apreender o significado que atribuem à realidade de suas ações (LUDKE; ANDRÉ, 1986).

O roteiro de perguntas foi elaborado a partir de questões levantadas pela diretoria da cooperativa acerca do Programa de Organização do Quadro Social (OQS), sendo aplicado aos cooperados nos meses de setembro, outubro e novembro de 2014, na área de atuação da cooperativa, com duração em média de cinco minutos (5 min) cada entrevista. Atualmente a cooperativa conta com 130 cooperados, e por apresentar um número relativamente pequeno de cooperados possibilitou a entrevista de 125 cooperados e os 5 cooperados que não puderam responder ao roteiro apresentaram justificativas como viagens e afastamento para tratamento médico. Os resultados encontrados na análise dos questionários e dos documentos disponíveis na cooperativa estão apresentados a seguir. A partir dos resultados obtidos houve um esforço para explicar, com base na literatura, o que leva o cooperado a tal comportamento.

\section{Resultados e discussões}

A cooperativa estudada contava até setembro de 2014 com 130 médicos cooperados, distribuídos em oito cidades da região Leste de Minas Gerais e a maioria residente em sua cidade sede. 
Os cooperados afirmam que, em média $10 \%$ da sua renda mensal é derivada das consultas e procedimentos efetuados pela cooperativa.

Nos últimos seis anos a cooperativa teve um baixo histórico de participação em assembleias (Figura 1). Quando consideradas as Assembleias
Gerais Ordinárias (AGOs) e extraordinárias (AGE) no período, os melhores anos em termos da participação dos associados foram os anos de 2009 e 2014 com um total de 66 e 46 cooperados, respectivamente.

Figura 1: Cooperados presentes em AGO e AGE

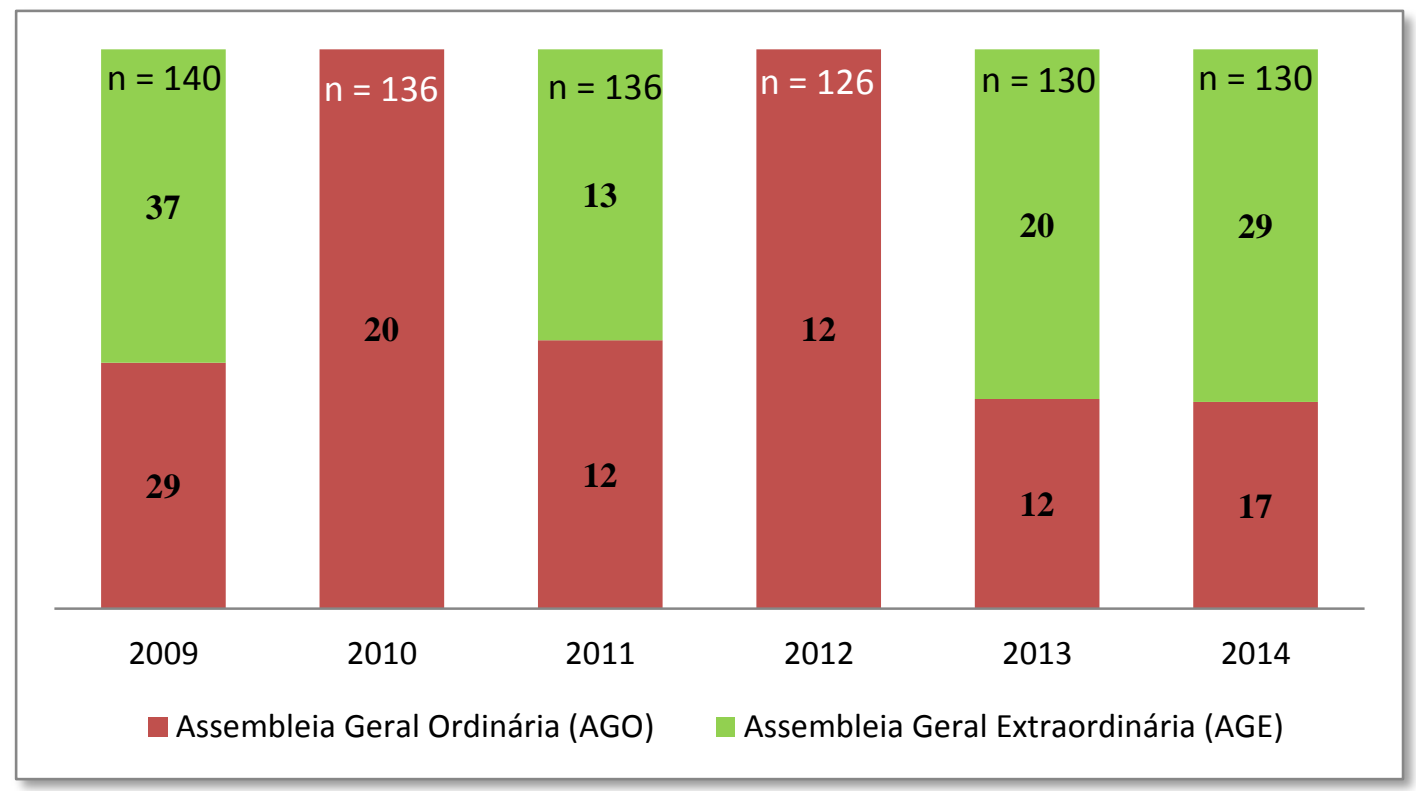

Fonte: Elaboração própria

De acordo com a Organização das Cooperativas Brasileiras (OCB), a Assembleia Geral Ordinária ( $\mathrm{AGO}$ ) deve ser realizada obrigatoriamente uma vez por ano, no decorrer dos três primeiros meses, após o encerramento do exercício social, para deliberar sobre prestações de contas, relatórios, planos de atividades, destinações de sobras, fixação de honorários, cédula de presença, eleição do Conselho de Administração e Fiscal, e quaisquer assuntos de interesse dos cooperados. Já a Assembleia Geral Extraordinário (AGE) deve ser realizada sempre que necessário e poderá deliberar sobre qualquer assunto de interesse da cooperativa. É de competência exclusiva da AGE a deliberação sobre reforma do estatuto, fusão, incorporação, desmembramento, mudança de objetivos e dissolução voluntária.

Percebe-se que no ano de 2009 houve uma AGE que contou com a presença de $26 \%$ dos cooperados, este fato se deve principalmente pelo assunto tratado nessa reunião, assunto esse que afetaria de forma direta os cooperados, como a construção de um laboratório próprio e a discussão da notificação de cancelamento do contrato de prestação de serviços aos clientes da cooperativa no único hospital da cidade. Já no ano de 2014 houve outra AGE que contou com a presença de $22 \%$ dos cooperados onde se discutiu a venda de um imóvel de propriedade da cooperativa.

\subsection{Como a participação pode influenciar no desempenho da cooperativa}

Diante desse histórico, buscou-se entender como a participação dos cooperados poderia contribuir para que a cooperativa tivesse um melhor desempenho.

Há uma situação provável de melhores preços e maior oferta de serviços, assim há participação 
econômica e maior transacionamento, mas a participação social do associado nas estruturas de decisão tende a diminuir, uma vez que poderá haver também uma consequente e mais intensa prestação de serviços oriunda dos melhores resultados econômicos. Por outro lado, se a cooperativa não apresenta um bom resultado em seu desempenho econômico, o custo de oportunidade da tomada de decisões se torna maior, bem como há uma tendência de que a oferta em serviços para os cooperados provavelmente diminua e assim a participação social nas estruturas de decisão na organização deverá diminuir progressivamente.

Desse modo, entende-se que a participação é essencial para o desenvolvimento e sucesso do cooperativismo, assim Ferreira (1999) ressalta a participação como uma das principais características que diferenciam as cooperativas das empresas. Segundo o autor, a cooperativa é uma empresa coletiva em que os associados participam tanto nas operações como nas decisões.

Logo, Fama e Jensen (1983) afirmam que, manter o processo de decisão nas mãos de admi- nistradores que não tenham os mesmos interesses dos proprietários, acarreta na necessidade de controle dos problemas da agência por meio de sistemas de decisões, que dividem o controle e monitoramento das decisões importantes em todos os patamares da organização da administração. Na concepção de Jensen e Meckling (1976), o conflito de agência surge a partir da separação entre a propriedade e a gestão empresarial. Em outras palavras, o principal delega ao agente o poder de decidir em nome da empresa. Porém, existe um potencial para conflitos de interesse entre os proprietários e os controladores quando a propriedade e o controle das corporações não coincidem, visto que o agente, seja por buscar maximizar interesses próprios, incompetência, negligência ou má-fé, pode não atuar em prol dos interesses dos proprietários. Esses fatos são demonstrados na figura 2 , na qual os médicos cooperados se justificam principalmente pelo trabalho com $28 \%$, horário com $22 \%$ e devido à delegação de poderes acaba por haver um desinteresse em participar das assembleias, logo se sente representado.

Figura 2: Causas apresentada pelos cooperados para a não participação nas assembleias

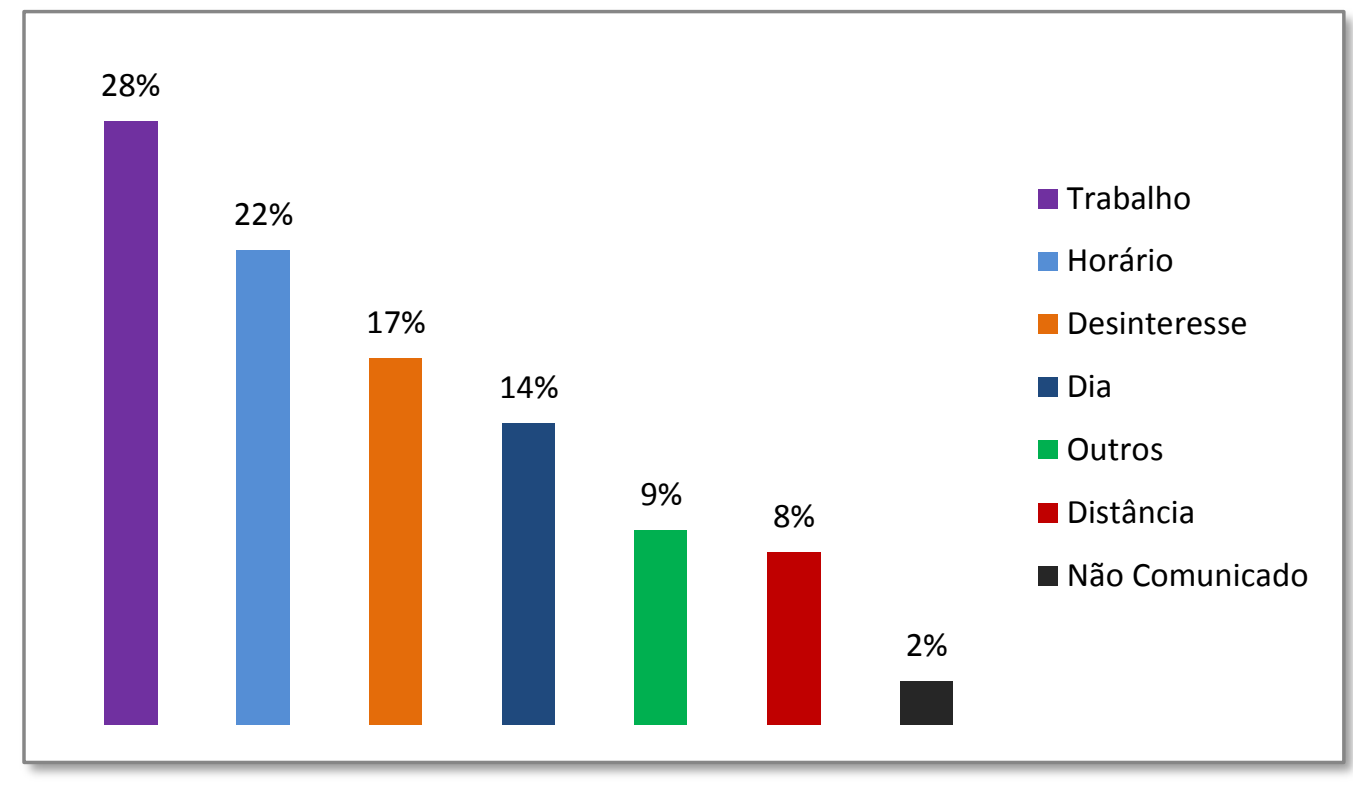

Fonte: Elaboração própria 
Assim sendo, o controle interno assume papel fundamental nas cooperativas. Conforme Bianchi (2005), esse conjunto serve para monitorar a gestão e o desempenho das organizações, por meio de um esforço contínuo em alinhar os objetivos da alta administração aos interesses dos acionistas ou proprietários. Dessa maneira, o controle interno pode assegurar que os dados gerados pelos sistemas não sejam distorcidos, garantindo a integridade dos atos e fatos administrativos, gerando relatórios e análise concisos, que reflitam a situação em cada momento na organização.

Para Meireles (1981), na administração de uma cooperativa deve-se levar em conta o envolvimento deste tipo de organização com metas específicas, relacionadas com a filosofia, valores e legislações próprias do cooperativismo. Além de sua importância intrínseca, a participação pode trazer vantagens tanto para as cooperativas quanto para os cooperados. De acordo com Sette, Sette e Souza (2005), a possibilidade das pessoas participarem ativamente da administração e dos resultados é o que há de mais moderno em uma sociedade, pois torna mais fácil a administração dos conflitos, logo as cooperativas não visam lucro enquanto organização, mas, visam atender aos objetivos sociais e econômicos dos seus associados, incluindo interesses comuns e, às vezes, dessemelhantes. Apesar da importância da participação social, pouco ainda é feito para incentivá-la e aumentá-la. Na maioria dos casos, a participação dos associados fica restrita ao econômico, ou seja, à entrega de produtos na cooperativa e à busca por serviços e preços vantajosos no que diz respeito à produção. Nessa perspectiva coletiva, as existências de objetivos comuns, a sensação de pertencimento e valores compartilhados, constituem se nos elementos que motivam à participação.

Além disso, devido às suas particularidades as cooperativas acabam por apresentarem características especiais que as diferenciam das demais sociedades, como a igualdade de direito dos sócios perante a sociedade cooperativa e o principio da variabilidade do Capital, são exemplos que as diferencia das demais organizações.

Segundo Stephanou e Villwock (2007), a maior preocupação dos cooperados com relação à participação é somente financeira, ou seja, eles estão interessados nos resultados, mas não no compromisso do modo como alcançá-los. Os autores salientam então que "para que a cooperativa funcione como organização econômica é preciso também, salientar o aspecto social" (p.150), pelo que se entende a participação efetiva em todas as atividades e decisões da cooperativa.

E por tal motivo a Sociedade Cooperativa é enquadrada no Código Civil como sociedade simples, não por acaso, mas porque é somente a partir daí que se pode falar em benefícios tributários e tratamento diferenciado. As Sociedades Limitadas Empresariais não possuem tratamento diferenciado constitucional, já que sua lucratividade é inerente ao modo de produção. As Sociedades Simples (Civis), por sua vez, podem ser constituídas com ou sem fins lucrativos, facilitando-se, assim, o trabalho de interpretação da legislação de defesa das cooperativas, dandolhes o tratamento diferenciado que merecem.

Portanto, na Legislação Tributária tem-se que a não incidência de tributos sobre o ato cooperativo ocorre em virtude do fato de não haver real transferência de titularidade, uma vez que os bens ingressam para realizar o objeto social, servindo-se os associados desses bens por sua condição de membros da sociedade cooperativa, suprimindo-se a intermediação e, por conseguinte, a mudança de titularidade dos bens (LEWIS, 2005, p.43).

Sette, Sette e Souza (2005 - p. 6) ressaltam, porém, que "as pessoas só participam daquilo que lhes interessa e daquilo que elas se sentem motivadas a participar". Desta forma, além de incentivos econômicos, a educação e a comunicação são fatores extremamente importantes para o associado sentir-se mais confiante e acreditar que é através da sua participação que a cooperativa pode alcançar voos maiores, atingindo assim seus objetivos e satisfazendo suas necessidades.

\section{Considerações finais}

Diante dos fatores limitantes à falta da participação, buscou-se entender como a participação dos cooperados poderia contribuir para que a cooperativa tivesse um melhor desempenho. Assim, percebe-se como a participação é inerente ao cooperativismo e essencial para o seu desenvolvimento e sucesso. Por se configurarem como 
sociedade de pessoas, as cooperativas devem dispor de mecanismos internos de participação, confiança mútua e voluntarismo nas ações. Assim, a existência de um modelo adequado de participação, de baixo custo e alta representatividade, mostra-se essencial para o sucesso das cooperativas e para o próprio fortalecimento dos ideais cooperativistas.

Adotando os pressupostos da teoria da agência, é necessário que a cooperativa crie estímulos adicionais, principalmente financeiros e com um senso de urgência e criticalidade para motivar a participação.

Do ponto de vista estritamente econômico, a motivação do associado em acompanhar os atos dos gestores deve ser proporcional ao risco que corre. De um modo geral, o participante é tentado a avaliar os benefícios e custos de seu envolvimento individual segundo uma racionalidade econômica. Se os benefícios ou riscos associados à decisão de participar ou não, são pequenas, as motivações para transferir a outras pessoas essa responsabilidade serão ampliadas, gerando espaço para uma postura de carona (free rider). Assim, para cumprir sua função social e econômica no contexto desenvolvimentista, é necessário que a cooperativa estabeleça procedimentos educacionais e de formação adequados ao seu funcionamento e finalidades e principalmente, que estes estejam adaptados às particularidades das organizações cooperativistas.

Levando em conta os aspectos da falta de participação, a cooperativa em questão mesmo apresentando uma baixa participação consegue ser eficiente no mercado por apresentar uma estrutura de gestão sólida e eficaz, além da busca por novas estratégias e treinamentos para qualificação dos gestores, colaboradores e cooperados da organização.

Dessa forma o grande desafio é entender como as cooperativas podem assegurar que os associados enfrentem riscos ainda menores em mercados cada vez mais competitivos, e ainda sejam capazes de manter a motivação dos cooperados para acompanharem a gestão e atuarem para evitar problemas relacionados a não participação, como o surgimento do carona.

\section{Referências}

ABRANTES, J. Associativismo e cooperativismo: como a união de pequenos empreendedores pode gerar emprego e renda no Brasil. Rio de janeiro: Interciência, 2004.

ANDRADE, M. F. S. Cooperativas sociais como possibilidade de trabalho e renda para o aluno com deficiência mental e sua família: uma revisão bibliográfica. Trabalho de Conclusão de Curso (Especialista) - Curso de Educação Profissional e Tecnológica Inclusiva, Instituto Federal de Educação Tecnológica de Mato Grosso, Cuiabá, 2009.

BIALOSKORSKI NETO. S.: Cooperativas: Economia, crescimento e estrutura de capital. Tese de Doutorado, ESALQ/USP, 1998.

BIALOSKORSKI, NETO. S. Estratégias e cooperativas agropecuárias: um ensaio analítico. In: SEMINÁRIO DE POLÍTICA ECONÔMICA. COOPERATIVISMO E AGRONEGÓCIO. Viçosa. Anais. Viçosa: Universidade Federal de Viçosa, Departamento de Economia Rural, out. 2002.

BIALOSKORSKI NETO. S. Gobierno y papel de los cuadros directivos en las cooperativas brasileñas: estudio comparativo. Revista de Economía Pública Social y Cooperativa, Valencia, n. 48, abr. 2004.

BIALOSKORSKI, NETO. S. Um ensaio sobre desempenho econômico e participação em cooperativas agropecuárias. Rev. Econ. Sociol. Rural vol.45 n. 1 Brasília Jan./Mar. 2007.

BIANCHI, M. A. Controladoria como um mecanismo interno de governança corporativa e de redução dos conflitos de interesse entre principal e agente. São Leopoldo: UNISINOS, 2005. Dissertação (Mestrado em Ciências Contábeis), Universidade do Vale do Rio dos Sinos, 2005.

<BRASIL. Lei $\mathrm{n}^{\circ}$ 5.764, de 16 de dezembro de 1071. Dispõe sobre as Sociedades Cooperativas>. Disponível em: 
http://www.planalto.gov.br/ccivil_03/Leis/L5764 .htm Acesso em: 02 de outubro de 2014.

BORDENAVE, J. E. D. O que é participação. São Paulo: Brasiliense, 1983.

CARNEIRO, P. P. Co-operativismo, o princípio cooperativo e a força existencial-social do trabalho. Fundec. Completer a referencia. 1981.

COOK, M. L. "The Role of Management Behavior in Agricultural Cooperatives." Journal of Agricultural Cooperatives, Vol. 9, 1994.

COOK, M. L. The future of U.S. agricultural cooperatives: a neo-institucional approach. American Journal of Agricultural Economics, Oxford, v. 77, n. 5, p. 1153-1159, Dec. 1995.

COOK, M. L. Understanding New Cooperative Models: An Ownership-Control Rights Typology. Review of Agricultural Economics, Vol. 26, 2004.

CULTI, M. N. Sócios do suor: Cooperativas de Trabalho. In: O Mundo do Trabalho e a Política. Maringá: EDUEM, 2006.

DOMINGUES, J. C. Cooperativas de trabalho: um modelo de autogestão no combate ao desemprego:verdades e mentiras. São Paulo: STF, 2002.

FAMA, E. F.; JENSEN, M. Separation of ownership and control. Journal of Law and Economis, v. 26, p 301-327, June 1983.

FERREIRA, R. N. Índices-padrão e situação econômica, financeira e político-social de cooperativas de leite e café da região sul do estado de Minas Gerais. Lavras: UFLA, P 138. 1999. (Tese de Mestrado).

FERREIRA, P. R.; PRESNO, N. B. A. O Sescoop e a criação do campo da educação cooperativista. In: ENCONTRO DE PESQUISADORES LATINOAMERICANOS DE COOPERATIVISMO,
2008, Ribeirão Preto. Anais... Ribeirão Preto: FEARP/USP, 2008.

FRONZAGLIA, T. Monitoring farm cooperative corporate governance. V Internation PENSA Conference on Agrifood Chains/Network Economics and Management, Ribeirão Preto, Faculdade de Economia, Administração e Contabilidade de Ribeirão Preto. Universidade de São, p. $1-13,2005$.

GIL, A. C. Métodos e Técnicas de Pesquisa Social. 1 ed. São Paulo: Atlas, 1987.

JENSEN, M. C.; MECKLING, W. H. Theory of the firm: managerial behaviour, agency costs and ownership structure. Journal of Financial Economics, v.3, p 05-360, 1976.

LAGO, A. Educação cooperativa: a experiência do programa do Sicredi. In: CONGRESSO DA SOCIEDADE BRASILEIRA DE ECONOMIA, ADMINISTRAÇÃO E SOCIOLOGIA RURAL, 46. 2008, Rio Branco. Anais... Rio Branco: Sociedade Brasileira de Economia, Administração e Sociologia Rural 2008.

HENDRIKSEN, E. S.; BREDA, M. F. V. Teoria da Contabilidade. São Paulo: Atlas 1999.

LEWIS, S. B. Tributação no Sistema Cooperativista. Revista FAE Business. Curitiba, $\mathrm{n}^{\circ} 12$, Set. 2005.

LIMA, M. A. T. F. C. O Cooperativismo Paranaense: Bases Históricas na sua Relação TeoriaPrática. Monografia (Curso de Especialização em Administração de Empresas) - Universidade Federal do Paraná. p 74. 1988.

LIMBERGER, E. Cooperativa: Empresa socializante. Porto Alegre, RS: Imprensa Livre. 1996

LÜDKE, M.; ANDRÉ, M. E. D. A. Pesquisa em educação: abordagens qualitativas. São Paulo: EPU, 1986. 
MENDES, A. P. S. Teoria da Agência Aplicada à Análise de Relações entre os Participantes dos Processos de Cooperação Tecnológica Universidade-Empresa. 2001. 260f. Tese (Doutorado em Administração) - Faculdade de Economia, Administração e Contabilidade, São Paulo, 2001.

MEIRELES, P. A. Ações administrativas e participação especial em cooperativa agropecuária: um estudo de caso em Minas Gerais. Lavras: Esal, 1981. 81p.(Tese de Mestrado).

MINAYO, M. C. de S. O desafio do conhecimento: pesquisa qualitativa em saúde. 3. Ed. São Paulo/Rio de Janeiro: Hucitec-Abrasco, 1994. 269p.

MÓGLIA, L. C.; PARADA, J. I.; BIALOSKORSKI, N. S.; MARCHI, D. Fidelidade e reciprocidade do cooperado: o caso da Carol. In: CONGRESSO DA SOCIEDADE BRASILEIRA DE ECONOMIA E SOCIOLOGIA RURAL, 42. 2004, Cuiabá. Anais... Cuiabá: Sociedade Brasileira de Economia e Sociologia Rural, 2004.

MORATO, A. F.; COSTA, A. Avaliação e estratégia na formação educacional cooperativista. In: MACÊDO, K. B.; XIMENES, J. A. A. (Orgs.). Cooperativismo na era da globalização. Goiânia: UCG/Terra, 446 p. 2001.

NASCIMENTO, F. R. Cooperativa como alternativa de mudança: uma abordagem normativa. Rio de janeiro: Forense, 2000.

NORONHA, O. M. Cooperativismo sóciocomunitário e educação: reflexões históricas e possibilidades atuais. In: Anais do VI Encontro de Pesquisa em Educação da Região Sudeste/ ANPED. Maio 2004.

OLIVEIRA, A. L. A Atuação da Incubadora Tecnológica de Cooperativas Populares da Universidade Regional de Blumenau: a Economia Solidária no Debate Acerca do Desenvolvimento Regional. Blumenau: URB, 2002. 187 p. (Dissertação de Mestrado).
OLSON, F. E. An empirical approach to exploring the role of selective incentives in mitigating the free rider problem. 2007. 205 f. Tese (Doutorado em Economia Agrícola) - Universidade de Missouri, Columbia, Estados Unidos da América.

ORGANIZAÇÃO DAS COOPERATIVAS BRASILEIRAS - OCB. Relatório de atividades 19942001. Brasília: Organização das Cooperativas Brasileiras, 2004. Disponível em: <http://www.ocb.org.br> Acesso em: 16 de outubro de 2014.

PERIUS, V. F. Cooperativismo e lei. São Leopoldo (RS): Ed.Unisinos, 351p. 2001.

PINHO, D. B. A empresa cooperativa. Administração de cooperativas. São Paulo: CNPq, 1982.

PINHO, D. B. Gênero e desenvolvimento em cooperativas: compartilhando igualdade e responsabilidades. ESETEC. Brasília: SESCOOP/OCB, 2000.

ROESCH, S. M. A. Projetos de Estágio e de Pesquisa em Administração. $3^{\text {a }}$. Ed. Ed. Atlas. São Paulo. 2000.

SANTOS, B. S. (Org.) PRODUZIR PARA VIVER. Os caminhos da produção não capitalista. $2^{a}$ ed. Rio de Janeiro, RJ: Civilização Brasileira, 2005.

SETTE, A. T. M. S.; SETTE, R. S.; SOUZA, M. A organização cooperativa sob a ótica dos cooperados. In: CONGRESSO DA SOCIEDADE BRASILEIRA DE ECONOMIA, ADMINISTRAÇÃO E SOCIOLOGIA RURAL, 43. 2005, Ribeirão Preto. Anais... Ribeirão Preto: Sociedade Brasileira de Economia, Administração e Sociologia Rural 2005.

SILVA, T. N. A participação de cooperados na gestão de cooperativas de produção: uma análise da separação entre propriedade e controle. Perspectiva Econômica, São Leopoldo (RS),UNISSINOS, v.29, n.86, jul./set. 1994. 
SCHNEIDER, J. O. Democracia, Participação e Autonomia Cooperativa. São Leopoldo: UNISINOS, 1991.

SCHULZE, E. Estrutura do poder em cooperativas. Perspectiva Econômica, São Leopoldo, v. 22, n. 59, p. 49-76, jun./dez. 1987.

STEPHANOU, L. C.; VILLWOCK, L. H. M. A percepção da democracia nas cooperativas médicas: O caso da Unimed Nordeste RS. Economia Solidária e Ação Cooperativa - ESAC, São Leopoldo, v. 1, p. 143-150, 2007.

VALADARES, J. H. Participação e poder: o comitê educativo na cooperativa agropecuária. Lavras: UFLA, 1995. 81 p. (Tese - Mestrado em Administração Rural). 